\title{
Direct flow drawing equipment performance reliability and increase of its effectiveness
}

\author{
Veronica Ivanova ${ }^{1}$ and Daniyar Madrakhimove, ${ }^{2, *}$ \\ ${ }^{1}$ Tashkent State Technical University named after I. Karimov, Tashkent, Uzbekistan \\ ${ }^{2}$ Tashkent State Technical University named after I. Karimov, Tashkent, Uzbekistan
}

\begin{abstract}
It is an analytic investigation of issues related to improving the efficiency and reliability of the drawing technological process, which are to be considered. After analytical efforts, a technical solution is proposed and justified. This technical solution is meant to improve the operational parameters of the cable products current-carrying conductor - reducing electrical resistance by reducing the fractional deformation and recalculating of the drawing sequence.
\end{abstract}

Keywords: Drawing, Cable And Wire Products, Drawing Machine, Drawing Mill, Technological Tool, Wire-Drawing Die, Drawing Block, and Electric Drive.

\section{Introduction}

Wire-drawing operations are the beginning of the manufacturing technology for all types of cableconductor products (CAT). This technical process provides a production of high-quality cable conductors [1]. An analysis of application of modern drawing technologies among manufacturers of cable-conductor equipment made it possible to conclude that jet drawing is the most common way among existing technologies.

All basic research in the field of increasing the reliability and efficiency of drawing technologies [2, 3, 4] led to the conclusion that the solution of the problems existing for the current production is provided mainly by technical re-equipment of enterprises, by equipping the production process with advanced technological equipment and modernizing the installed plant and equipment.

Actually efficiency improving of the drawing technological process may be achieved by using modern production lines in the production process, combining several technological operations; using so called multiwire drawing, when 8 until 56 wires are simultaneously being drawn; reduction of power consumption by technological equipment; the choice of the optimal parameters of the emulsion; service life extension of the technological tool - wire-drawing die; using high-quality die billets (wire rods); improvement processes of technologies and modernization of equipment with the introduction of resource-saving and energy-saving electromechanical systems (EMC) [4, 8].

An ultimate goal of the manufacturing process is to provide high operational characteristics of the technical checkpoint, including the low value of the electrical (true ohmic) resistance of the current-carrying conductor (CCC). At the same time, a well-established drawing technology, as an initial technological operation, has the greatest influence on the process of formation of the structure of the current-carrying conductor.

\section{Proposed technical solution description}

An analytic investigation of the methods which have been used to increase the efficiency of modern drawing machines (DMs) made it possible to conclude that the joint influence of factors to improve the quality of the drawn wire and simultaneously increase the energy and resource saving of the drawing technology cannot be solved at the same time.

In-depth study aiming to improve the quality of conductor resistance CR (undertaken by Sh. Berin and N.Z. Dniestrovsky) [5] allowed to reduce the electrical resistance of the wire during cold plastic deformation for copper to $3 \%$, and for aluminum to $1.5 \%$. This fact can be explained by the Drawing Theory (Fig. 1) for conductor resistance $\mathrm{CR}$, which depends on the magnitude of the drawn wire fractional deformation when passage through drawing sequences.

In reliance on technological equipment, the distribution of the applied drawing force, which is the total for the entire process (Fig. 2), is determined by the technical parameters of the main rod breakdown and wire-drawing machines. This process ensures the maintenance of tension in the pulling system of the wiredrawing machines. The calculation of the partial drawing forces of the intermediate pulling blocks and their proportional distribution depends on the calculated drawing ratio, the magnitude of the backward tension

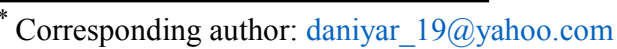


acting between the pulling and drawing blocks and is carried out through the drawing sequences for the entire process.

In compliance with the above suggested solution to the problem of reducing the electrical resistance of the current-carrying conductor (CCC), it is possible to achieve by reducing the fractional deformation at the price of reducing the number of passages through the drawing sequences, i.e. a decrease in the number of drawing passes and working zones of plastic deformation (technological tool - wire dies). Metal structural changes occur just at that spot.

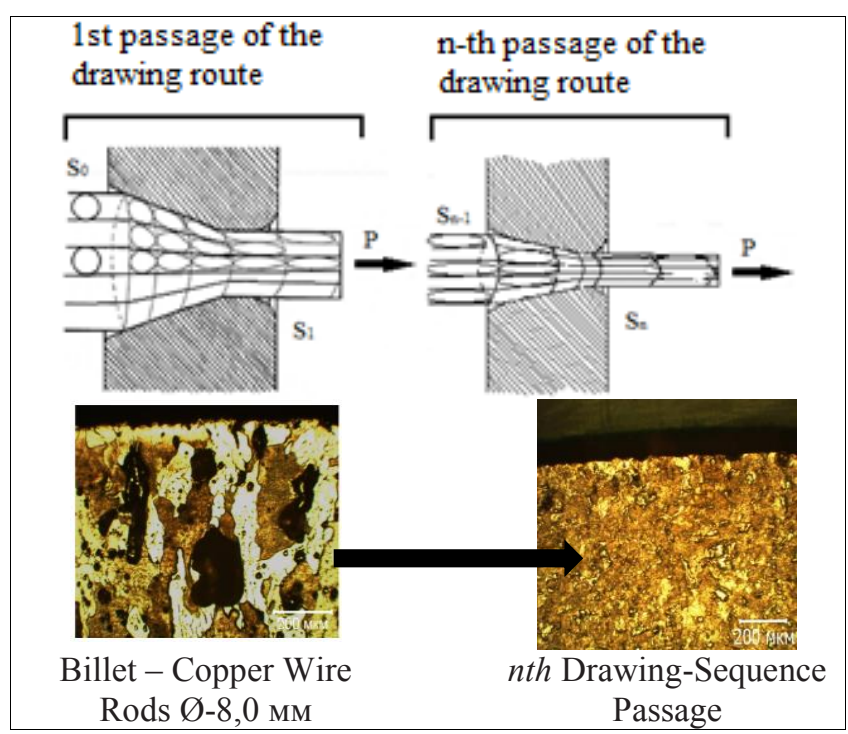

Fig. 1. Drawn Wire Structure Changes Diagram When Passage Through Drawing Sequence and Fractional Deformation Effect on Copper Wire Samples Micro Specimen.

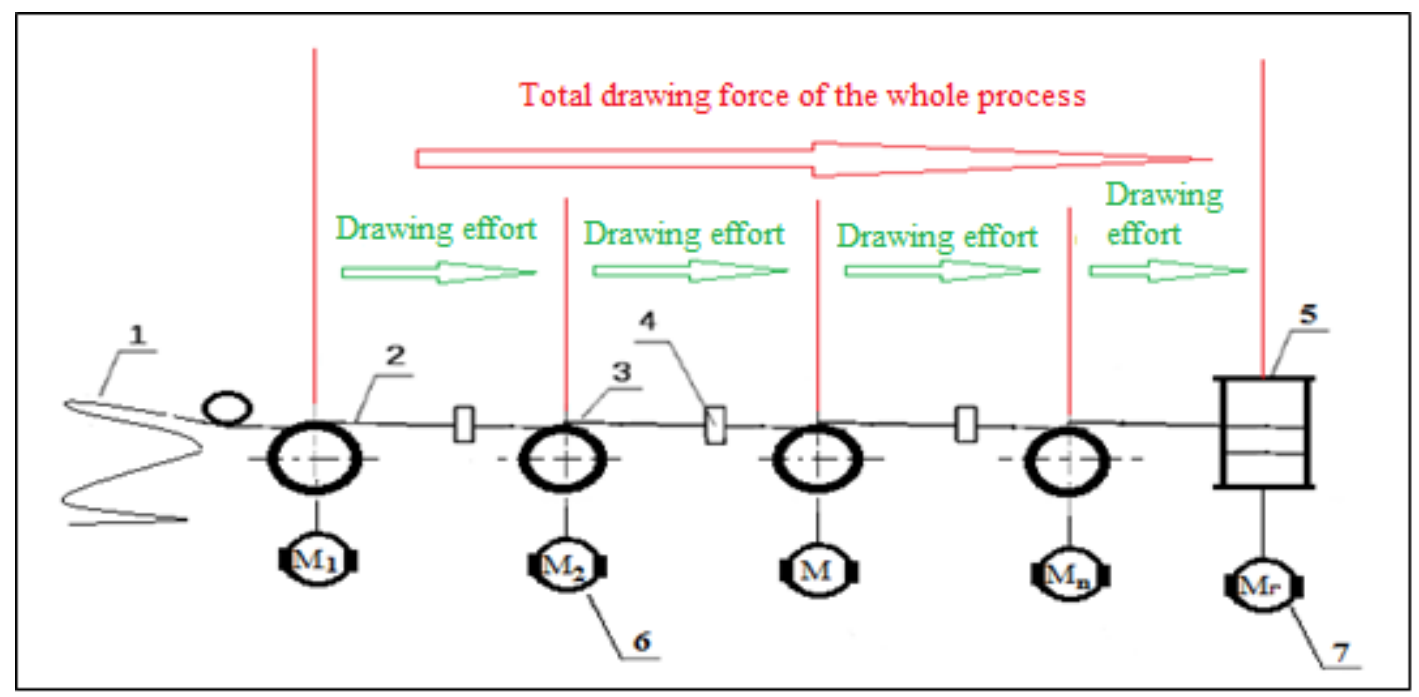

Fig. 2. Straight-Through Type Drawing Machine: 1- pay-off stand; 2- wire; 3- intermediate block; 4- process tool (wire drawing die); 5-reciever; 6- drawing block electro drive; 7- main drawing machine electro drive.

\section{Investigations' experimental part}

Exploratory tests were carried out on copper wire drawn samples in the testing laboratory of NAVOICABLECONNECTOR LLC (City of Navoi, Uzbekistan). During conducting a structural analysis of the microslices (Fig. 3.4), it was established that the microstructure of the sample undergoes compaction, which is explained by the presence of technological drawing action on the line of application of the drawing force. The measurements of the ohmic resistance of the samples confirmed [5] the deterioration of the electrical conductivity of the current-carrying conductor (CCC) due to the influence of the fractional strain that causes the compaction of the wire microstructure.

The experimental part has been carried out on a direct-flow VM (Fig. 2). It includes: pay-off stand (1), receiver (5) intermediate blocks system (3), as well as the main drawing electro drive machines (7), which produce the necessary drawing force and maintain the required tension in the electromechanical system "PayOff Stand - Receiver". There are also systems of individual electronic drives (6) mounted on the pulling blocks (3), and carrying out the wire pulling with predetermined intermediate wire diameters along the drawing passages. 


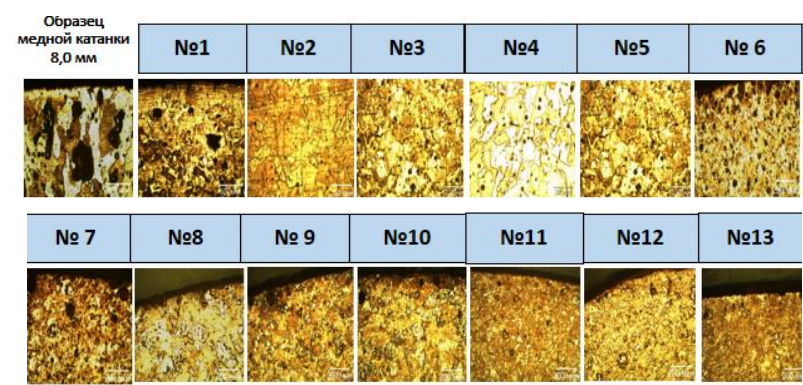

Fig. 3. Microstructure of Drawn Copper Current-Carrying Conductor Sample at VM VSK-13 (The example $8 \mathrm{~mm}$ copper rod).

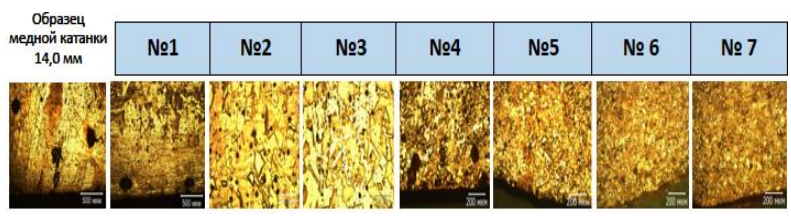

Fig. 4. Microstructure of Drawn Copper Shaped Wire Sample (The example $14 \mathrm{~mm}$ copper rod).
A new drawing passages readjustment to a smaller number of passages allowed to reduce the number of drawing passages from 10 to 6 and to exclude idle drawing blocks (DB) with individual electromechanical systems (EMC) from the technology. The obtained clipped samples studies results showed an improvement of the copper wire samples quality indicators (electrical conductivity) by an average of $15 \%$ (Fig. 5). The reduction in the number of unused EMCs led to a $27 \%$ decrease in energy consumption for straight-through type drawing machine (STTDM). It is a ground to consider the proposed technical solution as energy-saving.

The survey results obtained during researches, in terms of electrical conductivity of current-carrying conductor (CCC), will create good conditions for the efficient and low-cost transportation of electric energy in the power supply system and, accordingly, they can be considered as energy efficiency in relation to power transmission systems.

Before recounting the drawing process

\begin{tabular}{|c|c|c|c|c|c|c|c|c|c|c|}
\hline 0 & 1 & 2 & 3 & 4 & 5 & 6 & 7 & 8 & 9 & 10 \\
\hline $\begin{array}{l}\text { aye } \\
\text { a }\end{array}$ & onsity & & 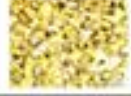 & E. & 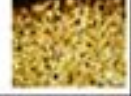 & 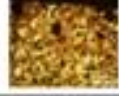 & & & & \\
\hline $8,00 \mathrm{MAs}$ & $6,8 \mathrm{MM}$ & $5,9 \mathrm{MA}$ & $5,2 \mathrm{MAs}$ & $4,6 \mathrm{MMM}$ & $4,0 \mathrm{MMS}$ & $3,5 \mathrm{ses}$ & $3,05 \mathrm{AMS}$ & $2,75 \mathrm{mat}$ & $2,43 \mathrm{MAS}$ & $2,14 \mathrm{xAM}$ \\
\hline \multicolumn{9}{|c|}{ Resistance $1 \mathrm{~m}$ at $20^{\circ} \mathrm{C}$} & \multicolumn{2}{|c|}{$0,0051 \mathrm{OM}_{\mathrm{M}}$} \\
\hline
\end{tabular}

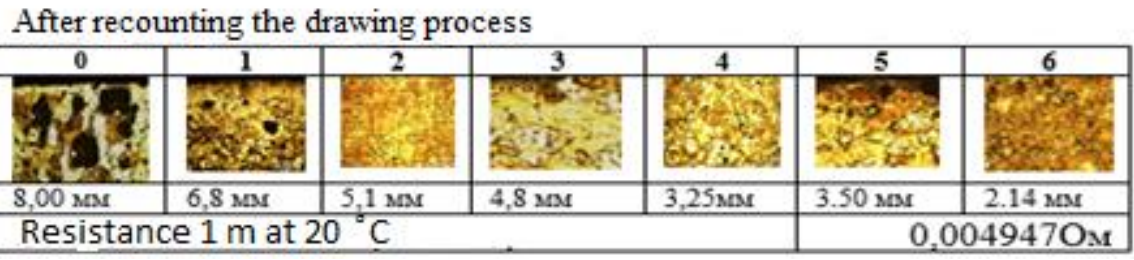

Fig. 5. Round Wire Samples Microstructure Alterations

\section{Mathematical modeling results}

In virtue of a generalized mathematical model $[2,9,10]$ of a straight-through type drawing machine (STTDM) (Fig. 6) and generalized requirements for electric drives (ED) [7], at the Electrical Machines Department of the Tashkent State Technical University, simulation results were obtained (1), taking into account the main drawing process parameters $[6,7,8]$, which made it possible to consider various options for the operation of a straightflow drawing bench and to determine the optimal multiplicity of the drawing process while ensuring the energy efficiency of the technology as a whole.

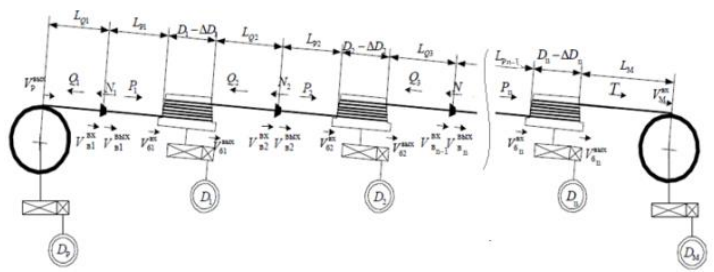

Fig. 6. The N-fold Straight-Flow Drawing Bench Design Scheme for Copper Wire Drawing $[2,7]$.
We investigated the EMC of the nth inter-drum span in a straight-through type drawing machine (STTDM) in relation to the present conditions under consideration of using the system of differential equations in the operator form [2].

$$
\begin{aligned}
& \mathrm{M}_{\text {дин } n}(p)=M_{\text {дв } n}(p)-P_{n}(p) \frac{R_{6}^{\mathrm{BX}}}{j_{\text {ред } n}}+ \\
& +Q_{(n-1)}(p) \frac{R_{6}^{\mathrm{Bux}}}{j_{\text {ред } n}}-\mathrm{M}_{\mathrm{xx}_{n}}(p) ; \\
& \omega_{\text {дв }_{n}}(p)=M_{\text {дин } n}(p) \frac{1}{J_{\sum n} p} ; \\
& v_{\sigma_{n}}^{\mathrm{BX}}(p)=\omega_{\text {дв } n}(p) \frac{R_{\sigma_{n}}^{\mathrm{BX}}}{j_{\text {ред } n}} ; \\
& v_{\sigma_{n}}^{\text {выx }}(p)=\omega_{\text {дв } n}(p) \frac{R_{\sigma_{n}}^{\text {вых }}}{j_{\text {ред } n}} ; \\
& P_{i}(p)=\left(v_{\sigma_{n}}^{\mathrm{Bx}}-v_{\mathrm{B}_{n}}^{\mathrm{Bdx}}\right) \frac{E F_{n}}{L_{p n} p} \\
& v_{\mathrm{B}_{n}}^{\mathrm{Bdx}}=v_{\mathrm{B}_{n}}^{\mathrm{Bdx}} \mu
\end{aligned}
$$


$v_{\mathrm{B}_{n}}^{\mathrm{BX}}=Q_{i}(p) \frac{L_{Q_{n}} p}{E F_{(n-1)}}+v_{\sigma_{(n-1)}^{\mathrm{Bdx}}}$

$Q_{n}(p)=P_{n}(p)-N_{n}(p)$

All experiments with numeric values to simulate the process of copper wire drawing, in order to determine the multiplicity of the drawing passages, were carried out using a generalized block diagram (Fig. 7) compiled on the basis of the system of equations (1).

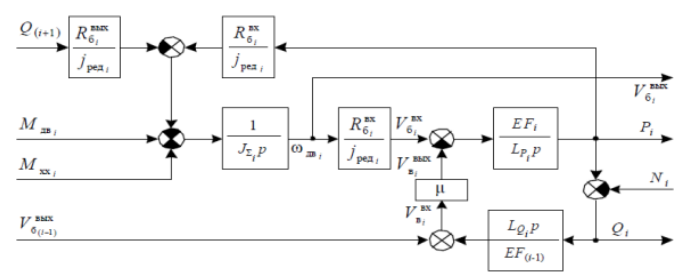

Fig.7. Mathematical Model Structure Diagram of the InterDrum Space [2].

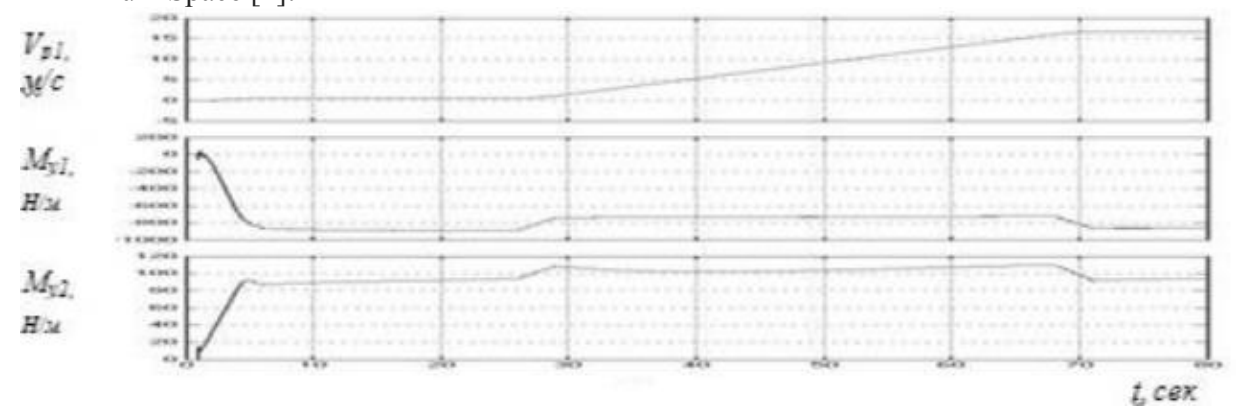

a)

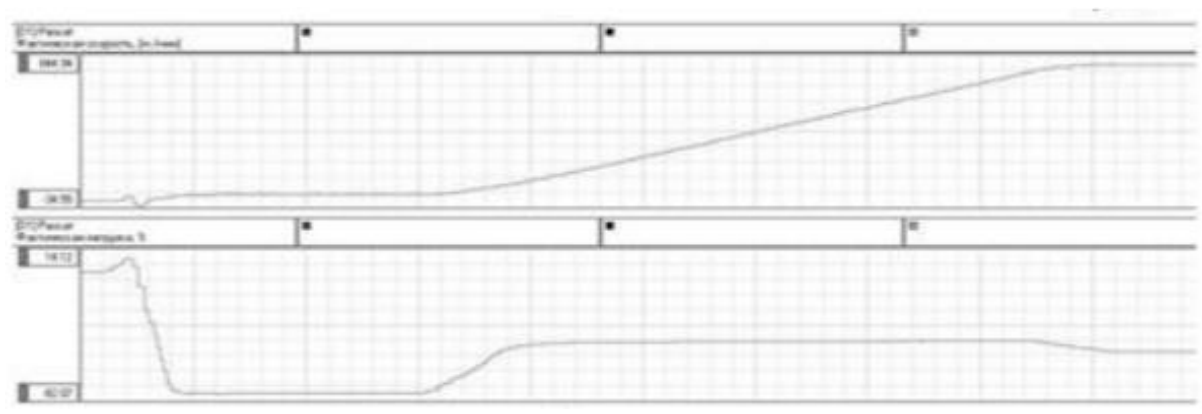

b)

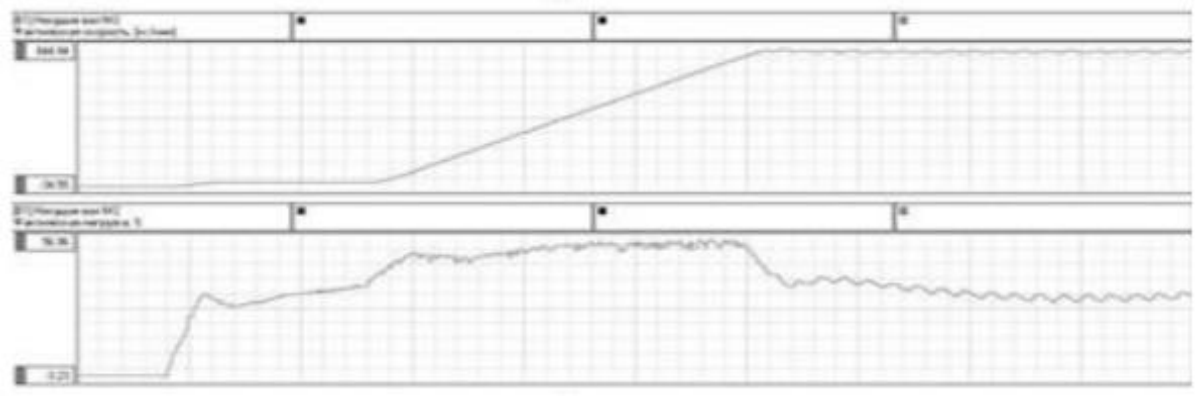

c)

Fig. 8. Simulation Results Fragments (a) and Industrial Experiments (b, c). 


\section{Conclusions}

The calculated data which we obtained and the results of an industrial experiment confirmed the correctness of the decision to turn off the electric motors of the wiredrawing machines pulling blocks (table-1). An industrial experiment was also carried out for drawing machines with a main electric drive (type VSK-13), however, positive results were obtained only by improving the quality parameters of stripped copper wire samples (reducing ohmic resistance). And, in relation to increasing the energy efficiency of the process for this particular case, other parameters remained unchanged. The reason - in the wire-drawing machine there is one main drive, which is, in kinematic sense of word, connected with the pulling drums, and therefore changing the passages to a given output diameter will be reduced to the number of dressed pulling washers.

Table 1. Comparative Analysis of Drawing Process Parameters

\begin{tabular}{|c|c|c|c|c|}
\hline \multirow{2}{*}{$\begin{array}{c}\text { Drawing } \\
\text { Process } \\
\text { Parameters }\end{array}$} & \multicolumn{2}{|c|}{ Total ED for VC } & \multicolumn{2}{|c|}{$\begin{array}{c}\text { Individual ED for } \\
\text { every TB }\end{array}$} \\
\hline & Current & Calculated & Current & Calculated \\
\hline $\begin{array}{l}\text { Passages q- } \\
\text { ty, number. }\end{array}$ & 10 & 6 & 7 & 5 \\
\hline $\begin{array}{l}\text { Electric } \\
\text { Motor } \\
\text { Quantity }\end{array}$ & \multicolumn{2}{|r|}{1} & 7 & 5 \\
\hline $\begin{array}{l}\text { Power } \\
\text { Input, kWt }\end{array}$ & \multicolumn{2}{|c|}{252} & 45 & 33,2 \\
\hline Material & \multicolumn{4}{|c|}{ Copper } \\
\hline $\begin{array}{l}\text { Drawn } \\
\text { Product }\end{array}$ & \multicolumn{2}{|c|}{ Round Wire } & \multicolumn{2}{|c|}{ Shaped Conductor } \\
\hline
\end{tabular}

The fact that the quality of process has been improved is not the only advantage of the proposed method. Significant savings can also be considered. Savings are due to:

- Reducing of drawing bench metal consumption;

- Reduction in the number of loaded gearboxes (gears), which led to a clear reduction in losses in the gear system of the machine as a whole;
- Reduction of expensive drawing tools details - drawing blocks, and, consequently, reduction of contact friction losses of tool surfaces with the object to be processed.

\section{References}

1. A.K. Bulkhin, V.F. Kidyaev, S.A. Kizhaev, Drawing Equipment Electric Drive and Automation, Part 1, 11, 381-394 (Samara, 2002)

2. S.A. Linkov, Mult. DF Draw. Bench Math. Mod. volume 159. Part 2 (St. Petersburg, 2004)

3. V.I. Zyuzin, V.A. Kharitonov, A.A. Radionov et al. Resource Saving in Wire Products: Collective Monograph 160 (Magnitogorsk, 2001)

4. V.V. Tsypkina, A.Sh. Akhmedov, D.B. Riksitullaeva, V.P. Tsypkina (Ivanova) Dev. of a Meth. for Impr. the Param. of Cop. Wire DDP // Energy and Res. Sav. Prob. (Special Issue) No. 3-4, 205 (Tashkent, 2013)

5. I.Sh. Berin, N.Z. Dniester, Copper and Aluminum Wire Production, Metallurgy Publishing House. 1617 (Moscow, 1974)

6. V.P. Ivanova, B.E. Yakubov Dev. of an Inf. Mod. for a Res.-Saving DM, No. 3, 36, (2017) URL: http://7universum.com/ru/tech/archive/item/4550 (accessed: 02.25.2019).

7. V.V. Tsypkina, A.A. Ivanov Dev. of Gen. Req. for Modern. of the DM Elec. Dr. for Cable Prod. No. 4, 37 (Moscow, 2017)

8. O.A. Troitsky, V.I. Stashenko, V.G. Ryzhkov, V.P. Lyashenko, E.B. Kobylskaya El.-plastic Dr. Proc. and New Tech. for CLW, No 4, 111-117 (2011)

9. Ivanova V.P., Kakhramonov Sh.K. Exp. Res. of a direct-flow DM. NAU, No. 43, Part 1, (2019)

10. Pirmatov N.B, Ivanova V. P., Madrakhimov D.B En. Ef. of Dr. Eq. thr. E\&R Sav. Int. Jour. of Adv. Res. in Sc., Eng. and Tech. Vol. 6, Issue 3, (March, 2019) 